\title{
Ruthenium Bottom Electrode Prepared by Electroplating for a High Density DRAM Capacitor
}

\author{
Oh Joong Kwon,** Seung Hwan Cha, and Jae Jeong Kim*,z \\ Research Center for Energy Conversion and Storage, School of Chemical Engineering, \\ Seoul National University, Kwanak-gu, Seoul 151-742, Korea
}

\begin{abstract}
The possibility of $\mathrm{Ru}$ electroplating for application as the bottom electrode in high density dynamic random access memory (DRAM) capacitors was investigated. Prior to Ru electroplating on a TiN substrate, HF cleaning and Pd activation were performed. Removal of Ti oxide from the TiN substrate by HF treatment enabled Pd activation, which enhanced the nucleation of Ru on TiN substrate. Optimized pretreatments led to a continuous Ru film deposition. The surface roughness was measured to be 4.4 $\mathrm{nm}$ at $45 \mathrm{~nm} \mathrm{Ru}$ film on the bare substrate. Moreover Ru electroplating method was also applied to a capacitor node-type TiN wafer. The deposition rate of Ru on the patterned wafer was the same as that on a bare wafer. The film showed $93 \%$ step coverage and good adhesion, comparable to CVD Ru films.

(C) 2004 The Electrochemical Society. [DOI: 10.1149/1.1637900] All rights reserved.
\end{abstract}

Manuscript submitted March 20, 2003; revised manuscript received August 18, 2003. Available electronically January 9, 2004.

As the device density of dynamic random access memory (DRAM) increases to gigabyte scale, the unit cell size, consisting of one transistor and one capacitor, decreases to $0.1 \mu \mathrm{m}^{2}$. As unit cell size decreases, the fabrication of $25 \mathrm{fF}$ capacitor has become a central issue in DRAM manufacturing. In the gigabit density era, the use of new materials with high dielectric constants $(\varepsilon)$ such as $\mathrm{Ta}_{2} \mathrm{O}_{5}$ and $(\mathrm{Ba}, \mathrm{Sr}) \mathrm{TiO}_{3}$ has been proposed as a new solution. ${ }^{1,2}$ In high dielectric material integration, a bottom electrode with high oxidation resistance and high work function is required. As the suitable metals which satisfy above two requirements, $\mathrm{Pt},{ }^{3,4} \mathrm{Pt} / \mathrm{Ru}$, and $\mathrm{Ru}$ were proposed.

Among these metals, Pt has been used as a bottom electrode. But oxygen diffusion and bad etching property have become problems in deep submicrometer dimension era. Alternatively, Ru film has recently attracted attention as a substitution of Pt because it can be easily patterned, has good etching property and forms oxygen diffusion preventing layer of $\mathrm{RuO}_{2}$ on top of $\mathrm{Ru}$ film during high $\varepsilon$ material deposition. $\mathrm{Pt} / \mathrm{Ru}$ is also considered to be suitable as a bottom electrode due to high work function and oxygen diffusion preventing layer of $\mathrm{RuO}_{2}$ at interface between $\mathrm{Pt}$ and $\mathrm{Ru}$. In spite of these advantages, it cannot be applied to deep submicrometer dimension era because it is too thick to apply to deep submicrometer dimension structure. From above description it can be concluded that $\mathrm{Ru}$ is the most promising material. ${ }^{5-8}$

Chemical vapor deposition $(\mathrm{CVD})^{8,9}$ and physical vapor deposition (PVD) ${ }^{10}$ have been widely used for the deposition of Ru films. These two processes have certain limitations including narrow process window, complex apparatuses, and high cost. In addition, rough surface morphology and poor step coverage are becoming important obstacles as feature size shrinks. Electroplating represents an alternative for the deposition of thin metal films because of good film quality, simple apparatus, and its low cost. In spite of these advantages, however, electroplating has rarely been used for depositing $\mathrm{Ru}$ film on semiconductor devices. ${ }^{11-17}$ The chief problems of Ru electroplating on a TiN substrate are Ru nucleation and limitation on the current distribution associated with high resistivity of the TiN barrier layer. ${ }^{18-20}$

In this study, Pd activation was investigated as a nucleus formation method to make Ru electroplating possible on TiN substrate. The size and density of nuclei were optimized, and Ru electroplating was carried out onto Pd activated TiN substrate. Then the quality of $\mathrm{Ru}$ film was estimated.

\footnotetext{
* Electrochemical Society Active Member.

** Electrochemical Society Student Member.

${ }^{\mathrm{z}}$ Electronic mail: jjkimm@snu.ac.kr
}

\section{Experimental}

The substrates used in this study were CVD TiN (10 nm)/PVD Ti $(15 \mathrm{~nm}) / \mathrm{Si}(100)$ blanket wafers and CVD TiN $(20 \mathrm{~nm}) / \mathrm{Si}(50 \mathrm{~nm}) /$ $\mathrm{SiO}_{2}$ patterned wafers (aspect ratio 2.5:1).

Prior to electroplating, two surface pretreatments on TiN substrate were performed sequentially. Ti oxide was removed from TiN substrate by using $1 \% \mathrm{HF}$ solution for $10 \mathrm{~min}$ followed by deionized (DI) water cleaning. Pd activation was done in the Pd activation solution of pH 2.57 composed of $\mathrm{PdCl}_{2}, 50 \% \mathrm{HF}(12.5 \mathrm{~mL} / \mathrm{L})$, and $\mathrm{HCl}(3.0 \mathrm{~mL} / \mathrm{L})$ while $\mathrm{PdCl}_{2}$ concentrations were varied from 0 to $0.4 \mathrm{~g} / \mathrm{L}$. The oxide free TiN substrate was dipped in Pd activation solution for $20 \mathrm{~s}$ and rinsed with DI water.

After pretreatment process, $\mathrm{Ru}$ electroplating was performed. $\mathrm{Ru}$ source and adjusting salt were W-RU2 (Japan Energy). The Ru electrolyte was made up of ruthenium sulfate solution $(5 \mathrm{~g} / \mathrm{L}), \mathrm{NaOH}$ $(40 \mathrm{~g} / \mathrm{L})$, and adjusting salt $(100 \mathrm{~g} / \mathrm{L})$. The adjusting salt was composed of phosphoric acid, sulfamic acid, and ammonium sulfamate. The $\mathrm{pH}$ of $\mathrm{Ru}$ electrolyte was 1.3 . A constant $-1.3 \mathrm{~V}$ potential was applied by a PAR 263 (EG\&G Princeton Applied Research Corporation) with respect to saturated calomel electrode (SCE) at room temperature. And the current density was $42 \mathrm{~mA} / \mathrm{cm}^{2}$ with this applied potential. Electroplating was carried out on both bare wafer and patterned wafer at the same condition.

The $\mathrm{Ru}$ film was characterized using field emission scanning electron microscopy (FESEM), X-ray photoelectron spectroscopy (XPS), X-ray diffraction (XRD) measurement, atomic force microscopy (AFM), and Auger electron spectroscopy (AES). The resistivity of ruthenium film was measured using the standard four-pointprobe method.

\section{Results and Discussion}

To find out an optimum $\mathrm{Pd}$ activation condition, $\mathrm{PdCl}_{2}$ concentrations were varied from 0.025 to $0.4 \mathrm{~g} / \mathrm{L}$. The deposited Pd particles were analyzed by XPS and FESEM as shown in Fig. 1 and Fig. 2. Both $\mathrm{Pd}$ and $\mathrm{PdCl}_{2}$ were found on the activated TiN substrate.

According to AFM analyses, the size of the Pd particle increased in proportion to $\mathrm{PdCl}_{2}$ concentration. It was smaller than $5 \mathrm{~nm}$ below $0.025 \mathrm{~g} / \mathrm{L} \mathrm{PdCl}_{2}$ concentration, and larger than $10 \mathrm{~nm}$ above 0.4 $\mathrm{g} / \mathrm{L} \mathrm{PdCl}{ }_{2}$ concentration. Pd densities were almost same to be 8.25 $\times 10^{10} / \mathrm{cm}^{2}$, independent of $\mathrm{PdCl}_{2}$ concentration of 0 to $0.4 \mathrm{~g} / \mathrm{L}$ at $1 \% \mathrm{HF}$ concentration. Figure $3 \mathrm{a}$ to $3 \mathrm{e}$ show the difference in density due to the shading of large particles over small ones. Among different $\mathrm{PdCl}_{2}$ concentrations, $\mathrm{Pd}$ activation with $0.1 \mathrm{~g} / \mathrm{L} \mathrm{PdCl}_{2}$ showed the most uniform size distribution and the smallest surface roughness of $2.9 \mathrm{~nm}$ as shown in Fig. 2 and 3c.

For variable Pd activation conditions Ru electroplating was performed on TiN substrate as shown in Fig. 4. Below the concentra- 


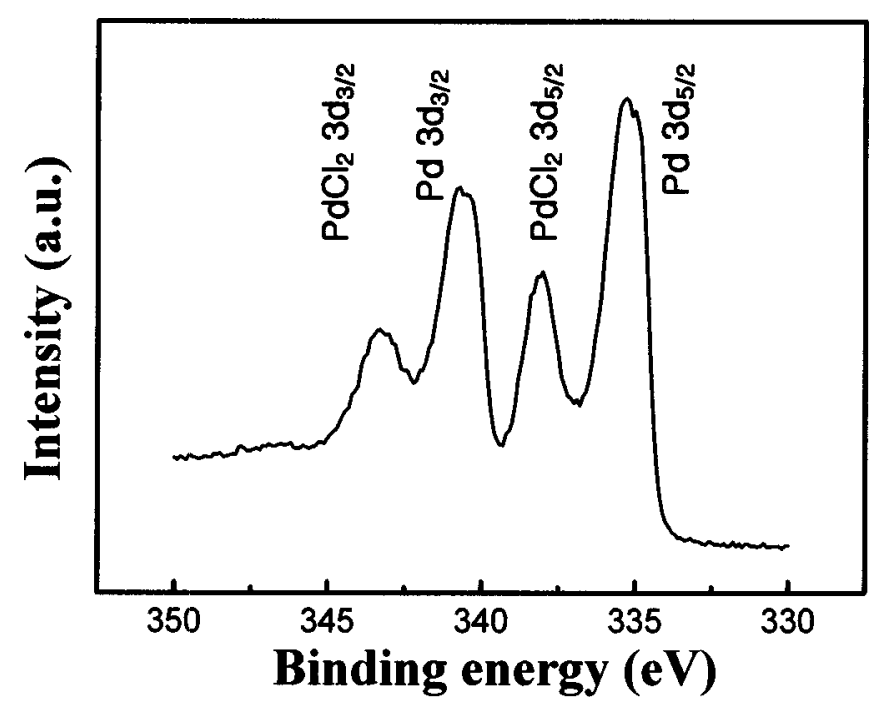

Figure 1. XPS spectrum of TiN substrate activated with $0.1 \mathrm{~g} / \mathrm{L} \mathrm{PdCl}_{2}$.

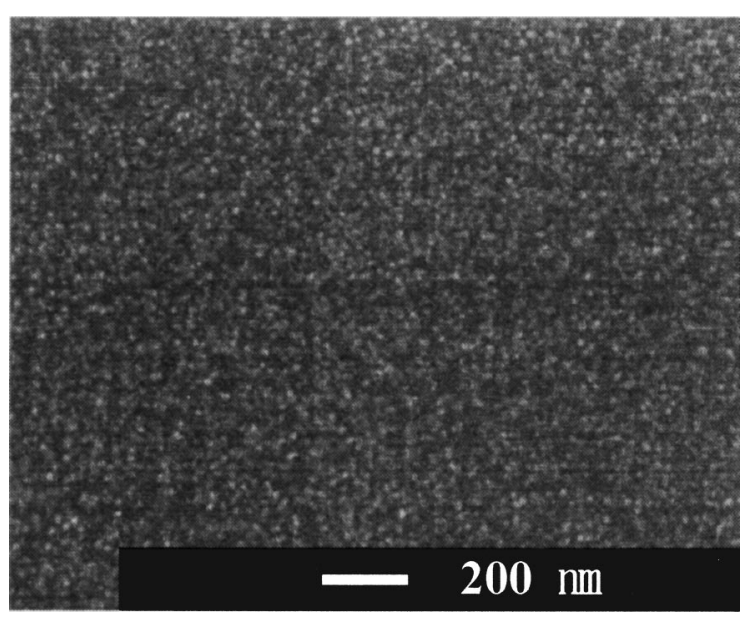

Figure 2. Surface FESEM image of TiN substrate activated with $0.1 \mathrm{~g} / \mathrm{L}$ $\mathrm{PdCl}_{2}$.
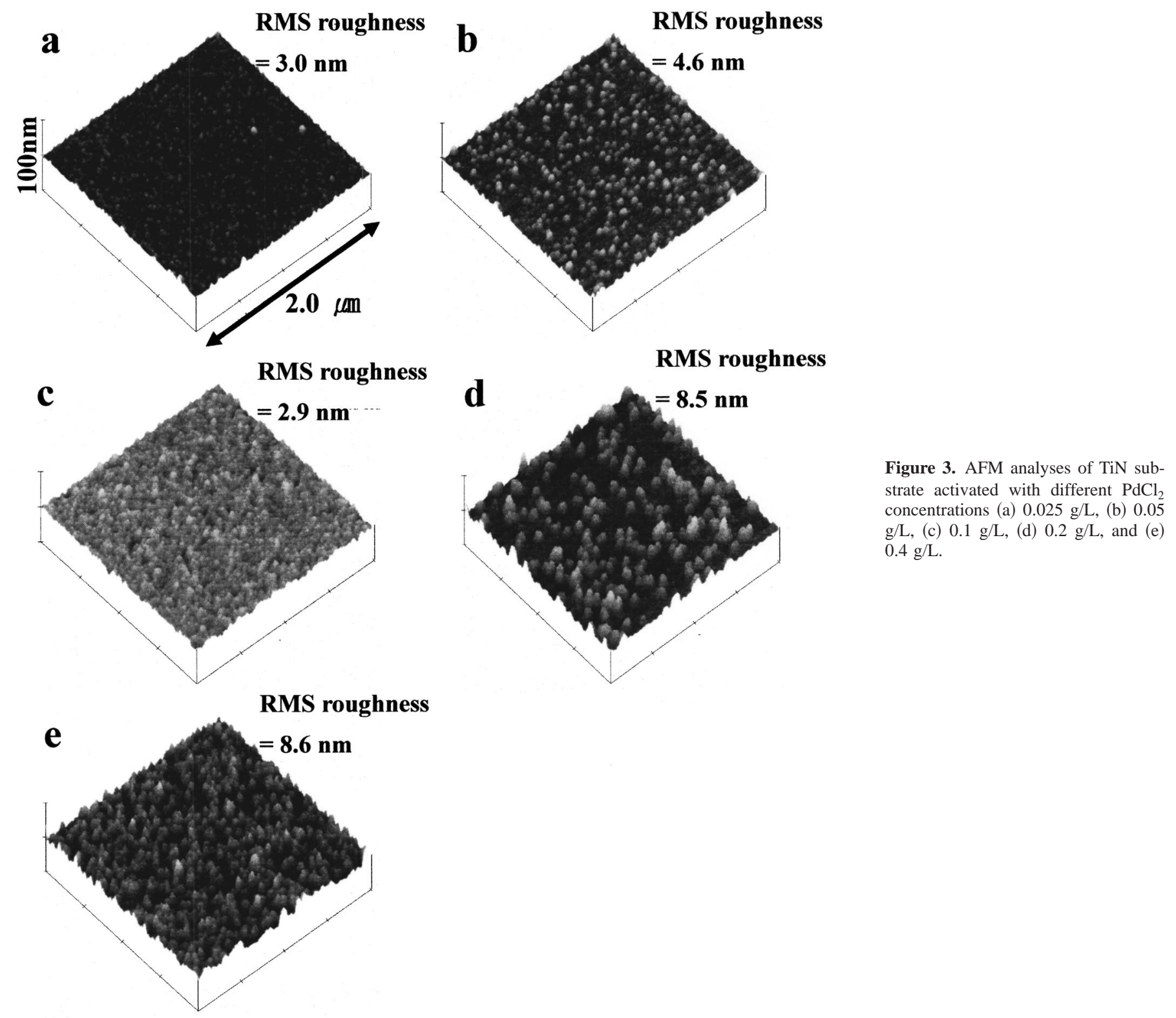

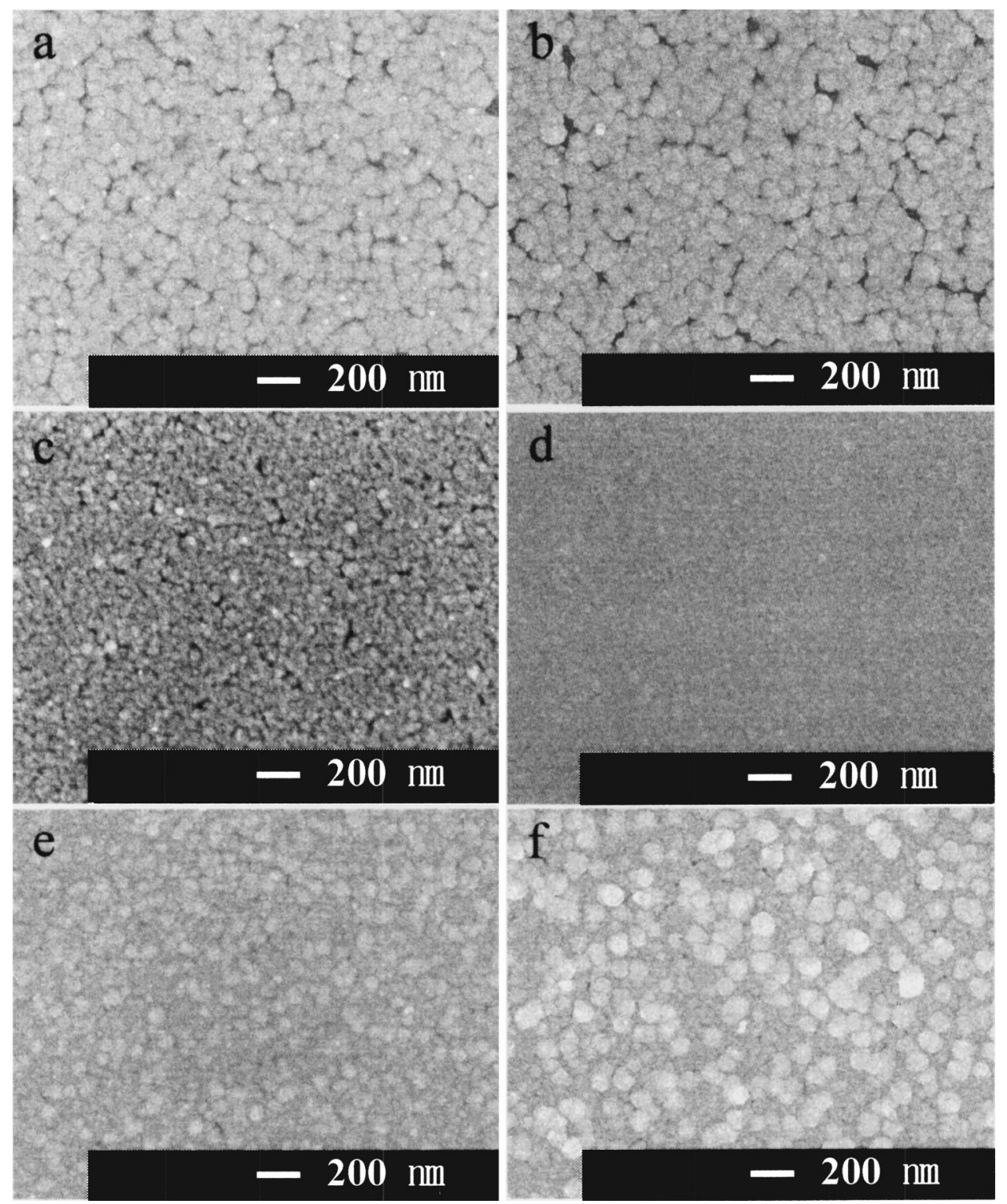

Figure 4. Surface FESEM images of Ru film activated with $\mathrm{PdCl}_{2}$ concentration of (a) $0 \mathrm{~g} / \mathrm{L}$, (b) $0.025 \mathrm{~g} / \mathrm{L}$, (c) $0.05 \mathrm{~g} / \mathrm{L}$, (d) $0.1 \mathrm{~g} / \mathrm{L}$, (e) $0.2 \mathrm{~g} / \mathrm{L}$, and (f) $0.4 \mathrm{~g} / \mathrm{L}$.

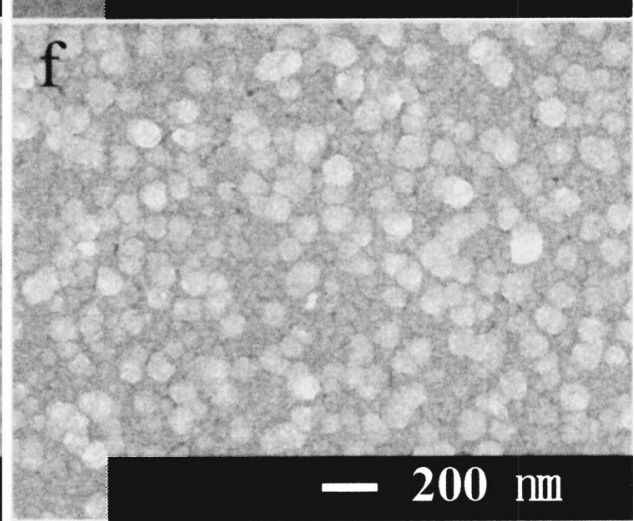

tion of $0.1 \mathrm{~g} / \mathrm{L} \mathrm{PdCl}{ }_{2}$, the $\mathrm{Ru}$ film was not continuous and in the range of 0 to $0.025 \mathrm{~g} / \mathrm{L} \mathrm{PdCl}_{2}$, Ru cluster size and surface morphology were almost identical. These phenomena reveal that Pd particles below $5 \mathrm{~nm}$ do not work as the nucleation centers. In the range of 0.05 to $0.1 \mathrm{~g} / \mathrm{L} \mathrm{PdCl}_{2}$ concentration, Ru clusters became smaller and a continuous Ru film was obtained. However, for Ru films activated above $0.2 \mathrm{~g} / \mathrm{L} \mathrm{PdCl}{ }_{2}$ concentration, the Ru clusters were larger and the surface morphology was rougher compared with films activated in solution with 0.05 to $0.1 \mathrm{~g} / \mathrm{L} \mathrm{PdCl}_{2}$. This is ascribed to the larger $\mathrm{Pd}$ particle size associated with the $0.2 \mathrm{~g} / \mathrm{L} \mathrm{PdCl}_{2}$ (Fig. $4 \mathrm{e}$ and f). These observations indicate that there is an optimum $\mathrm{PdCl}_{2}$ concentration for making Ru film continuous and smooth. A near optimum $5 \mathrm{~nm} \mathrm{Pd}$ particle size was obtained in a $0.1 \mathrm{~g} / \mathrm{L} \mathrm{PdCl}_{2}$ at $1 \% \mathrm{HF}$ solution. The thickness and surface morphology of a Ru film deposited from a $0.1 \mathrm{~g} / \mathrm{L} \mathrm{PdCl}_{2}$ solution are shown in Fig. $5 \mathrm{a}$ and b. Film thickness was $45 \mathrm{~nm}$ and root mean square (rms) surface roughness was $4.4 \mathrm{~nm}$. The RMS surface roughness was below $10 \%$ of Ru film thickness and which enabled application as a bottom electrode of a DRAM capacitor. And the adhesion of Ru film was tested with American Society for Testing and Materials (ASTM) tape test method. Ru film was not peeled off by tape test method.
To investigate the compositional characteristics and crystalline structures of Ru film, AES, XPS and XRD analyses were performed. Carbon contamination was checked by using low intense Ru (MNN) peak because high intense Ru (MNN) peak overlaps with carbon (KLL) peak in AES analysis and by comparing the area ratio of $\mathrm{Ru} / \mathrm{RuO}_{2}$ of $3 \mathrm{~d}_{5 / 2}$ peak with that of $3 \mathrm{~d}_{3 / 2}$ peak in XPS analysis. Carbon was not detected in both analysis methods. In the AES analysis, it is found that some oxygen is contained in the Ru film and Pd particles exist at the interface of Ru and TiN (Fig. 6a). It can be inferred from Fig. $6 \mathrm{~b}$ that the oxygen content in the Ru film corresponds to $\mathrm{RuO}_{2}$. Four overlapping peaks at 280.0, 280.7, 284.2, and $284.7 \mathrm{eV}$ were observed in XPS data. Among them, 280.0 and $284.2 \mathrm{eV}$ correspond to the $3 \mathrm{~d}_{5 / 2}$ and $3 \mathrm{~d}_{3 / 2}$ binding energy of $\mathrm{Ru}$, and 280.7 and $284.7 \mathrm{eV}$ indicate the $3 \mathrm{~d}_{5 / 2}$ and $3 \mathrm{~d}_{3 / 2}$ binding energy of $\mathrm{RuO}_{2}$. Moreover, XRD analysis points out that $\mathrm{RuO}_{2}$ is amorphous (Fig. 7), in which a weak and broad peak around $35.16^{\circ}$ reveals $\mathrm{RuO}_{2}$. Therefore it can be concluded that the electroplated $\mathrm{Ru}$ film is the composite film of $\mathrm{Ru}$ and $\mathrm{RuO}_{2}$. The ratio of $\mathrm{RuO}_{2}$ to $\mathrm{Ru}$ is $1 / 24$ in the middle of as-deposited film, which was calculated with AES data by considering sensitivity factor and stoichiometric number. And the ratio of $\mathrm{Ru} / \mathrm{RuO}_{2}(1 / 3$ in AES analysis and $1 / 2$ in 

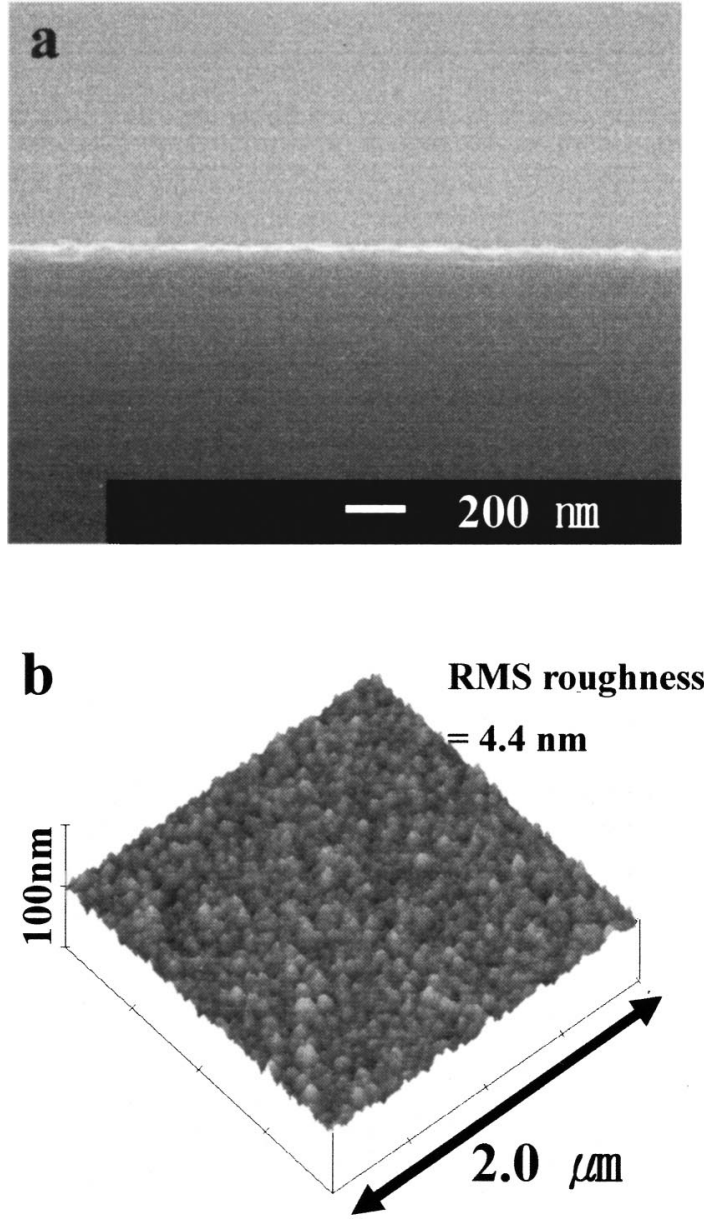

Figure 5. (a) Cross sectional FESEM image of Ru film activated with 0.1 $\mathrm{g} / \mathrm{L} \mathrm{PdCl}_{2}$, and (b) AFM analysis of Ru film activated with $0.1 \mathrm{~g} / \mathrm{L} \mathrm{PdCl}_{2}$.

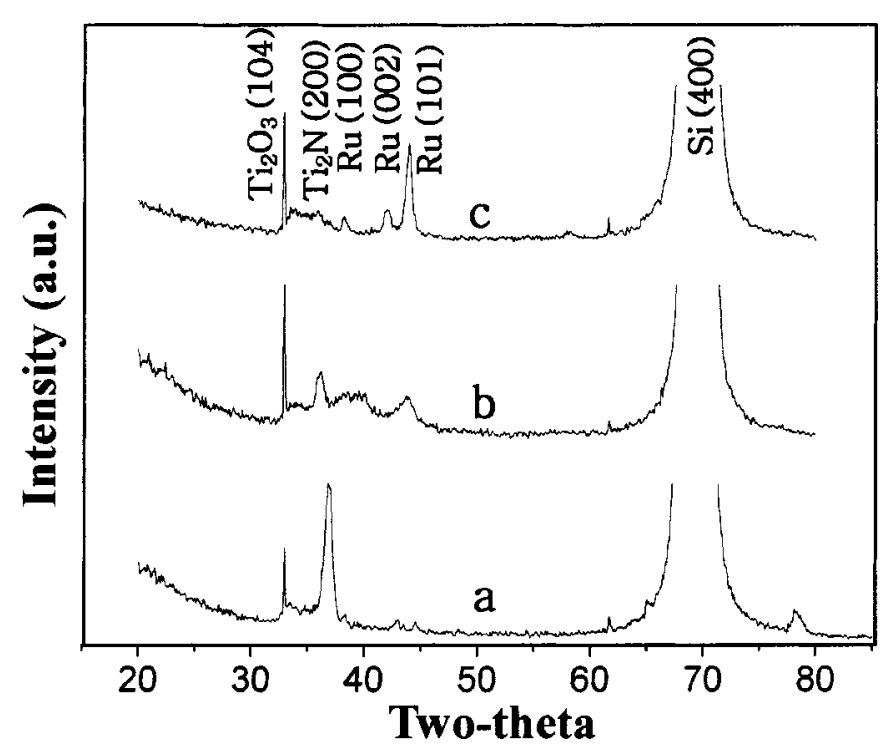

Figure 7. XRD patterns of (a) TiN substrate, (b) Ru film after electroplating, and (c) Ru film after anneal process at $500^{\circ} \mathrm{C}$ for $10 \mathrm{~min}$ in air atmosphere.
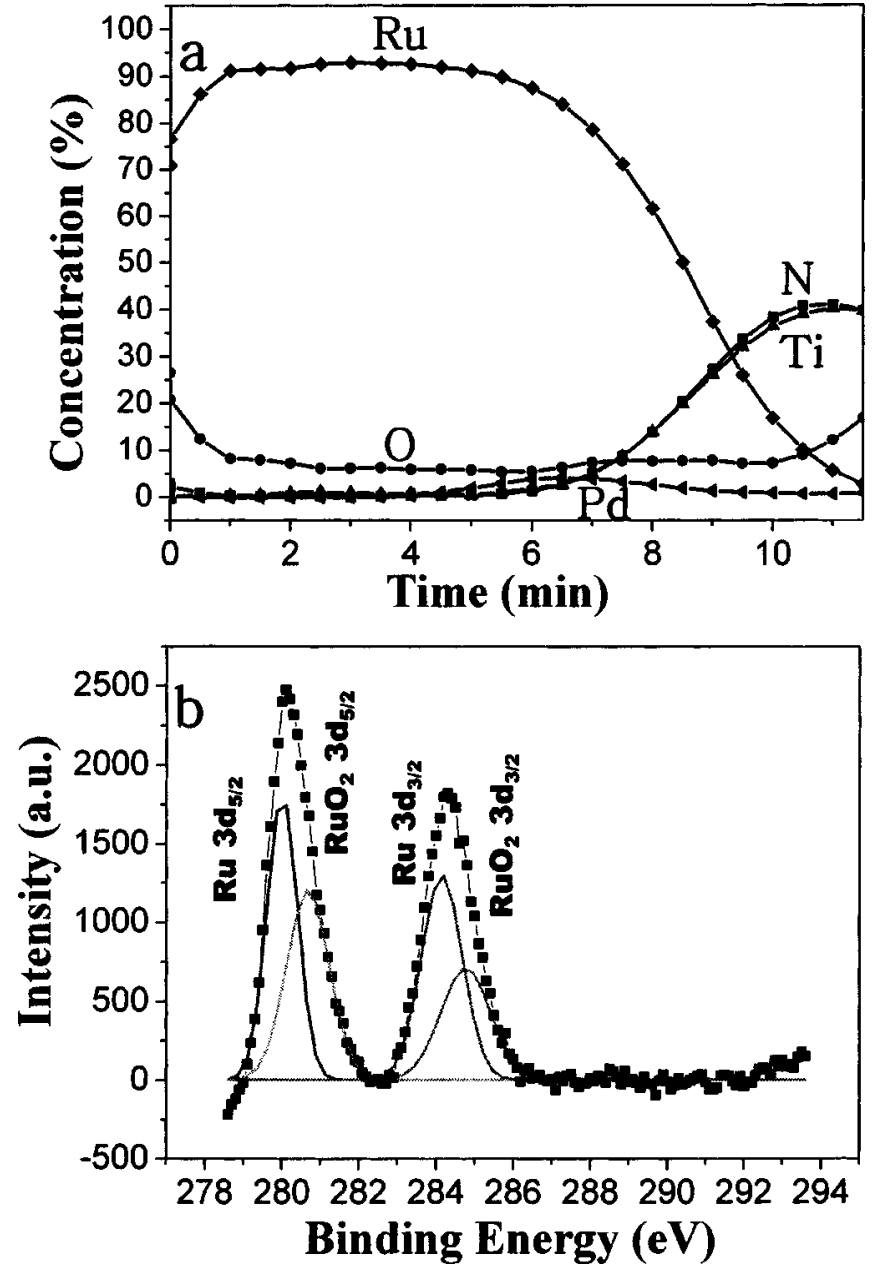

Figure 6. (a) AES depth profile of Ru film activated with $0.1 \mathrm{~g} / \mathrm{L} \mathrm{PdCl}_{2}$ and (b) XPS spectrum of Ru film activated with $0.1 \mathrm{~g} / \mathrm{L} \mathrm{PdCl}_{2}$.

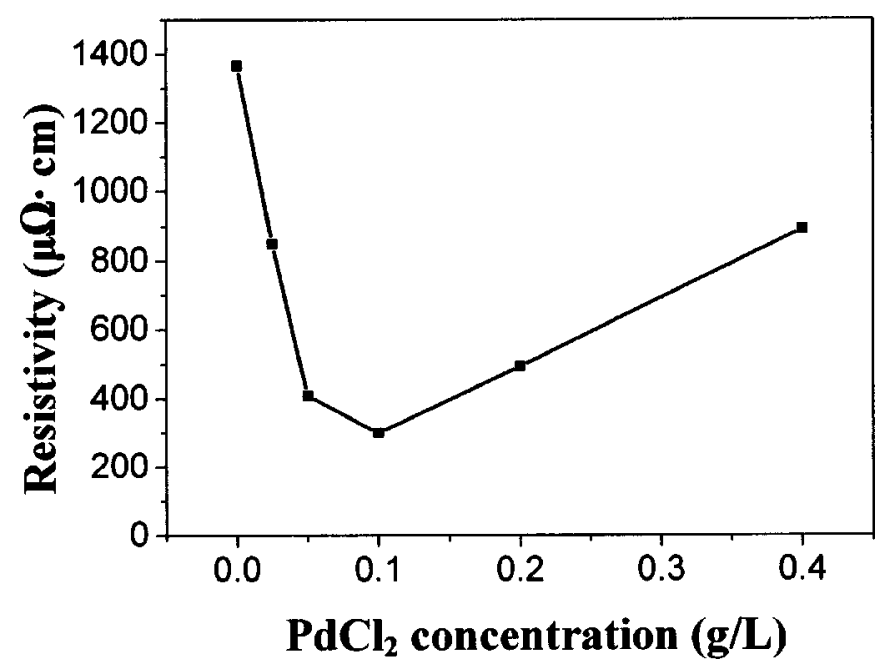

Figure 8. Trend of resistivity of electrodeposited Ru film. 

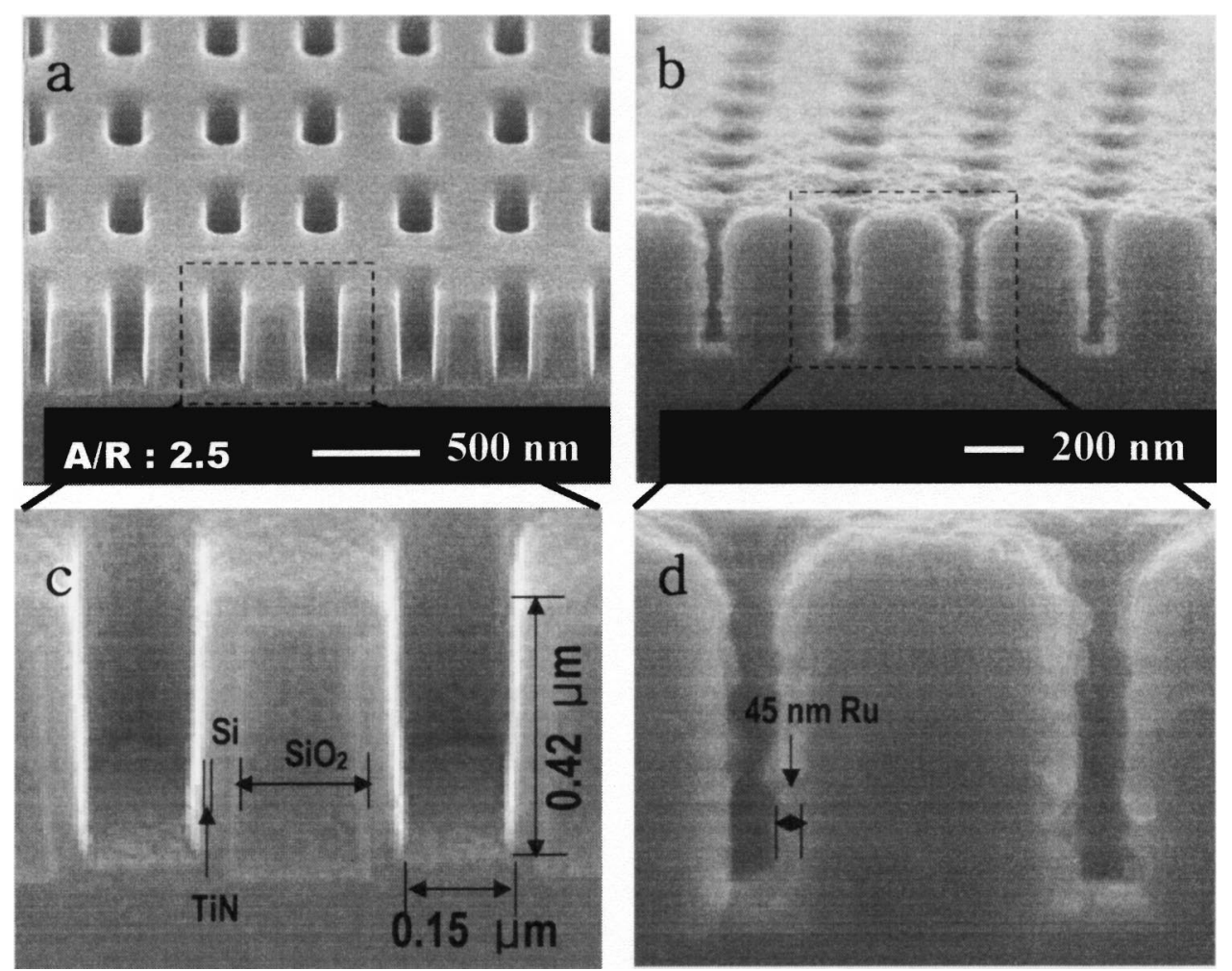

Figure 9. FESEM micrographs of (a) patterned TiN wafer, (b) Ru film on patterned TiN wafer, (c) patterned TiN wafer (enlarged), and (d) Ru film on patterned TiN wafer (enlarged).

XPS analysis) is lower at the surface than in the middle of film due to native oxide. Inclusion of oxygen into the middle of film is hard to be avoided in solution experiment due to high affinity of $\mathrm{Ru}$ to oxygen. ${ }^{21,22}$ Thus to remove oxygen content from Ru film, posttreatment such as electrical reduction and anneal were suggested and showed possibility. These processes are to be studied.

As-deposited Ru film showed small cluster size and poor crystalline structure by XRD pattern in Fig. 7b. But after anneal process at $500^{\circ} \mathrm{C}$ for $10 \mathrm{~min}$ in air, (101) preferred orientation was obtained and (100), (002) peaks appeared during anneal because of grain growth and recrystallization. By comparing Fig. 7a with $7 \mathrm{~b}$, it can be seen that a $\mathrm{Ti}_{2} \mathrm{~N}$ (200) peak shifted to the left after annealing, so that compressive stress is applied to Ru film.

The trend of resistivity of Ru film is shown in Fig. 8. The resistivity of $300 \mu \Omega \mathrm{cm}$ of as-deposited Ru film in Ru film deposited by electroplating is relatively higher than that of metallorganic CVD (MOCVD) Ru film. It is believed that small cluster size, poor crystalline structure and impregnated amorphous $\mathrm{RuO}_{2}$ contribute to the high resistivity. With annealing process, however, this high resistivity of $\mathrm{Ru}$ film can be further reduced to $38 \mu \Omega \mathrm{cm}$ due to grain growth and recrystallization of $\mathrm{Ru}$, which is comparable to the resistivity of MOCVD Ru film. Oxidation of Ru in the film did not occur during annealing because thin $\mathrm{RuO}_{2}$ layer formed on top of the film prevented further diffusion of oxygen. ${ }^{3}$

The optimized process condition of Ru electroplating onto bare wafer was applied on capacitor node-type TiN patterned wafer to examine the possibility of Ru electroplating to real DRAM fabrication method. The minimum feature size of TiN wafer used in this study was $0.15 \mu \mathrm{m}$ with $2.5: 1$ aspect ratio, and the structure of substrate was CVD TiN $(20 \mathrm{~nm}) / \mathrm{Si}(50 \mathrm{~nm}) / \mathrm{SiO}_{2}$ as shown in Fig. 9. The experimental conditions including $0.1 \mathrm{~g} / \mathrm{L} \mathrm{PdCl}_{2}$ activation were the same as those in the bare wafer experiment. In patterned wafer, the film thickness was about $45 \mathrm{~nm}$, which is the desired node thickness to $0.1 \mu \mathrm{m}^{2}$ cell size DRAM application with the consideration of the thickness of $\mathrm{Ta}_{2} \mathrm{O}_{5}$ and it of top electrode. And the deposition rate was $7.5 \mathrm{~nm} / \mathrm{min}$, which is the same value in the bare wafers. The pattern was well covered with $\mathrm{Ru}$ film throughout a wafer, showing $93 \%$ step coverage and smooth surface morphology. And it also showed good adhesion.

\section{Conclusion}

The possibility of Ru electroplating for application as the bottom electrode fabrication method of a high-density DRAM capacitor was investigated. Without the Pd activation process, a discontinuous $\mathrm{Ru}$ film was obtained due to the low density of nucleation center. But after $\mathrm{Pd}$ activation was performed with $0.1 \mathrm{~g} / \mathrm{L} \mathrm{PdCl}_{2}$ for $20 \mathrm{~s}$ on TiN wafer, a continuous Ru thin film was obtained. After electroplating, the $\mathrm{Ru}$ film had $45 \mathrm{~nm}$ thickness, $7.5 \mathrm{~nm} / \mathrm{min}$ deposition rate, and $4.4 \mathrm{~nm}$ surface roughness. These are appropriate value for DRAM application. The resistivity of electroplated Ru film was high compared with that of MOCVD Ru film, but it could be further reduced by annealing. A reduced resistivity of $38 \mu \Omega \mathrm{cm}$ was obtained although the optimal annealing conditions have not been established. With a capacitor node-type wafer, Ru electroplating also showed the same thickness as bare TiN wafer, acceptable surface roughness, 93\% step coverage, and good adhesion. These results indicate that $\mathrm{Ru}$ electroplating is comparable to $\mathrm{Ru}$ MOCVD method.

\section{Acknowledgment}

This work was supported by KOSEF through the Research Center for Energy Conversion and Storage (RCECS) and also by Institute of Chemical Processes (ICP), and Inter-university Semiconductor Research Center (ISRC).

Seoul National University assisted in meeting the publication costs of this article.

\section{References}

1. J. W. Lee, K.-M. Kim, H.-S. Song, K.-C. Jeong, J. M. Lee, and J. S. Rho, Jpn. J. Appl. Phys., Part 1, 40, 5201 (2001)

2. S. Ezhilvalavn and T.-Y. Tseng, Mater. Chem. Phys., 65, 227 (2000).

3. H. N. Al-Shareef, X. Chen, D. J. Lichtenwalner, and A. I. Kingon, Thin Solid Films, 280, 265 (1996).

4. K. L. Saenger, G. Costrini, D. E. Kotecki, K. T. Kwietniak, and P. C. Andricacos, J. Electrochem. Soc., 148, C758 (2001). 
5. Y.-S. Kim, R. H. Rampersad, and G. R. Tynan, Jpn. J. Appl. Phys., Part 2, 37, L502 (1998).

6. T. Aoyama and K. Eguchi, Jpn. J. Appl. Phys., Part 2, 38, L1134 (1999).

7. E.-S. Choi, J.-C. Lee, J.-S. Hwang, and S.-G. Yoon, Jpn. J. Appl. Phys., Part 1, 38, 5317 (1999).

8. T. Aoyama, M. Kiyotoshi, S. Yamazaki, and K. Eguchi, Jpn. J. Appl. Phys., Part 1, 38, 2194 (1999)

9. J. J. Kim, D. H. Jung, M. S. Kim, S. H. Kim, and D. Y. Yoon, Thin Solid Films, 409, 28 (2002)

10. J. Lin, N. Masaaki, A. Tsukune, and M. Yamada, Appl. Phys. Lett., 74, 2380 (1999).

11. V. Horvat-Radošević, K. Kvastek, M. Vuković, and D. Cukman, J. Electroanal. Chem., 482, 188 (2000).

12. K. A. Friedrich, K.-P. Geyzers, A. Marmann, U. Stimming, and R. Vogel, Int. J. Res. Phys. Chem., 208, 137 (1999).
13. H. A. Gasteiger, N. Markovic, P. N. Ross, and E. J. Cairns, J. Phys. Chem., 97, 12020 (1993).

14. Y. S. Chang and M. L. Chou, J. Appl. Phys., 69, 7848 (1991).

15. J. Scherzer and A. M. Weisberg, U.S. Pat. 3,530,049 (1970).

16. J. N. Croshy, U.S. Pat. 4,082,625 (1978).

17. T. Jones, Met. Finish., 99, 6, 121 (2001).

18. A. Radisic, J. G. Long, P. M. Hoffmann, and P. C. Searson, J. Electrochem. Soc. 148, C41 (2001).

19. L. Graham, C. Steinbruchel, and D. J. Duquette, J. Electrochem. Soc., 149, C390 (2002).

20. K. M. Takahashi, J. Electrochem. Soc., 147, 1414 (2000).

21. A. S. Arico, S. Srinivasah, and V. Antonucci, Fuel Cells, 1, 133 (2001).

22. K. L. Ley, R. Liu, C. Pu, Q. Fan, N. Leyarovska, C. Segre, and E. S. Smotkin, J. Electrochem. Soc., 144, 1543 (1997). 